\title{
Countermeasures and suggestions regarding the development of low carbon transport
}

\author{
Jianfang Zong, ${ }^{*}$, Liang Sun, Huiting Guo, Fei Fang \\ China National Institute of Standardization \\ No.4 Zhichun Road, Haidian District, Beijing
}

\begin{abstract}
The transport industry is the main sector of China's energy consumption, while the urban transport is the main way of China's carbon emissions. Therefore, the development of low carbon transport is not only the significant way to mitigate greenhouse gas emissions, but also the inevitable trend for future development of transport industry. This paper introduces the present status and fundamental connotation, characteristics and implementation path of low carbon transport. On such basis, this paper illustrates the international experiences of low carbon transport, and analyzes the main problems existing in the development of urban low carbon transport in China. This paper also provides the countermeasures and suggestions regarding the development of low carbon transport in China.
\end{abstract}

\section{Present status and fundamental connotation of low carbon transport}

The low carbon transport is a concept proposed under the background of global response to climate change and a sort of transport development pattern with the fundamental characteristics of low energy consumption, low emission and low pollution. In addition, its core is to enhance the energy-consuming efficiency of transport, improve the energy-consuming structure of transport and mitigate the carbon emissions of transport. The low carbon transport is the low energy consumption and low emission transport method that aims at reducing the greenhouse gas emissions of transport behavior, and a sort of realization method of low carbon economy within the transport field. The low carbon transport is a systematic project, which not only involves the transport itself, but also has the close relationship with the land utilization, vehicle engineering technology and infrastructure. In addition, each system branch also involves the resources, transport, energy and other fields which are interlinked, and keeps in touch with the outer systems [1].

Globally, the largest carbon emission industry is the power industry, which accounts for $40 \%$ of total carbon emissions. It is followed by the transport industry, which accounts for $21 \%$ of total carbon emissions. Therefore, the transport industry is the significant field where the low carbon economy may be developed, resulting in the presence of low carbon transport. In essence, the low carbon transport is the transport featuring the high energy efficiency, low energy consumption, low pollution and low emission. The core of low carbon transport is to enhance the energy-consuming efficiency of transport, improve the energy-consuming structure of transport and optimize the development method of transport. Low carbon transport aims at forcing the transport infrastructure and public transport system to finally reduce the high strength consumption of high carbon energy represented by the conventional fossil energy, and its measurement index is the carbon emissions [2].

The UK is the first country to propose the "low carbon" concept in the world. In 2003, the "low carbon economy" concept was proposed for the first time in the UK's white paper Our Energy Future - Creating a Low Carbon Economy. In 2009, the "low carbon transport" concept was proposed in China for the first time in the working arrangements of two executive meetings of the State Council regarding the response to climate change, clearly proposing to "accelerate the establishment of the industrial, architecture and transport system featuring the low carbon emissions".

In 2014, the Ministry of Transport proposed to accelerate the development of "comprehensive, smart, green and safe transport". The green transport stresses the relationship between transport development and environment, which aims at resources saving, energy efficiency enhancement, emission control and environmental protection. Compared with the green transport, the low carbon transport puts more emphasis on the "low emission" concept. In other words, it minimizes the energy consumption and greenhouse gas emission, and answers the carbon emission value under two scenarios before and after the implementation of low carbon measures, and the improvement degree of transport status. Therefore, the low carbon transport is the basis and prerequisite of green transport and the necessary means to realize the green transport.

\footnotetext{
* Corresponding author: zongjf@enis.ac.cn
} 


\section{Characteristics of low carbon transport}

The concrete category of low carbon transport may be discussed from four parts, namely, fundamental emission characteristics, structural characteristics, technical characteristics and institutional characteristics. In other words, the fundamental emission characteristics present the low emission, low energy consumption and high energy efficiency; with regard to the structural characteristics, the transport structure squints towards cleaning, publicity and high-efficiency, while the infrastructure structure squints towards rationalization and technicalization; with regard to the technical characteristics, it presents the "three highs" situation, namely, high proportion of clean and low carbon type fuel, high emission efficiency of transport means and high degree of informatization utilization; with regard to the institutional characteristics, it demonstrates the strict environmental control standards, advanced management system, integrated management pattern and other low carbonization features.

(1) Low carbonization. The development of transport is the process that is committed to continuously "reduce the carbon". As the means of transport must rely on the energy, it is hard for the transport to reach the carbonfree status. Instead, it is only feasible to continuously repeat the low carbonization development process, except for the use of clean energy (such as solar energy, wind energy and etc.).

(2) Emission reduction. Both "energy saving" and "emission reduction" are significant means to realize the low carbonization of transport. As a result, not only the emphasis shall be placed on the "energy saving", but also the "emission reduction" shall be ascended to its proper height.

(3) Systemaltization. The low carbon transport is a systematic concept. Either the planning, construction, maintenance and operation of transport system, or the production, use and maintenance of transport means, or even the relevant institutional and technical guarantee measures, the travel mode and transport consumption pattern, and etc., shall be transformed and optimized by the "low carbonization" concept.

(4) Comprehensiveness. On one hand, there are variable methods of low carbonization, and the technical, structural and institutional carbon reduction are all its means. On the other hand, the low carbon path is bidirectional, which includes not only the carbon emission reduction with regard to the "supply" or "production", but also the carbon emission reduction with regard to the "demand" or "consumption".

\section{Implementation path of low carbon transport}

The urban transport is a composite system consisting of five fundamental elements, namely, people, vehicle, fuel, road and transport system management. Therefore, the so-called low carbon transport shall be realized from four aspects, namely, travel demand management, vehicle policy, road policy and fuel policy.

\subsection{Travel demand management}

One of the paths for reducing the carbon emissions of transport system is the conduct of travel demand management. The so-called travel demand refers to the movement of people's spatial position which may be completed either by the services provided by the transport service provider or by the consumer himself/ herself. The travel itself is not the purpose. Instead, the final purpose is to complete variable tasks at the destination via the travel. Hence, the reduction of carbon emission generated during the travel process may be realized via two methods: firstly, optimize the urban spatial distribution, so as to reduce the people's travel demand; secondly, encourage people to select the low carbon travel method, so as to realize the target of reducing the carbon emission at the same travel distance.

\subsection{Vehicle-based emission reduction policy}

The motor vehicle is the core element for realizing the low carbon transport. At present, many countries in the world have introduced a series of policies for restricting the possession of motor vehicle and controlling the use of motor vehicle, so as to solve the environmental pressure resulted from the growth of motor vehicle inventory. For instance, the motor vehicle quota system is adopted by Singapore, Shanghai and Beijing in China, and the collection of higher purchase tax and registration fee and other financial policies are adopted by most countries in the world. Furthermore, in order to control the oil consumption of motor vehicle, at least 9 countries or regions in the world have already executed or submitted the relevant fuel economy standards at present. Now, the fuel economy standards have already been recognized as one of the most effective means for the government to control the oil consumption and carbon emissions of motor vehicle both at home and abroad.

\subsection{Road-based emission reduction policy}

At present, the road-based emission reduction policy in China is mainly demonstrated in the relevant policies of giving priority to the development of public transport, which mainly includes:

(1) Bus rapid transit (BRT). At present, the BRT has already been constructed and operated in many cities in China, such as Beijing, Guangzhou, Hangzhou, Suzhou, Zhengzhou, Dalian, Changzhou, Jinan, Zaozhuang, Hefei, Kunming, Xiamen, Chongqing, Yancheng, Urumqi, Nanchang, Changsha, Shenzhen, Shenyang, Lanzhou and etc.

(2) Rail transit. It mainly includes the subway, light rail, magnetic levitation, tramcar and other means of transport. At present, the BRT has already been constructed and operated in many cities in China, such as Beijing, Tianjin, Shanghai, Nanjin, Wuhan, Chongqing, Dalian, Changchun, Taipei, Kaohsiung, Xi'an, Hong 
Kong, Guangzhou, Shenzhen, and etc. The rail transit facilitates relieving the urban traffic congestion and reducing the use ratio of private cars.

\subsection{Fuel-based emission reduction policy}

The development of alternative fuels for vehicles and the collection of fuel tax are two significant carbon emission reduction policies. Among them, the alternative fuels for vehicles are considered as the significant strategic choice for all countries in the world to reduce the transport carbon emissions. Meanwhile, the fuel tax is the significant policy to guide the consumers to reasonably consume vehicle fuels, reduce the road transport consumption and mitigate the carbon emission.

\section{International experience of low carbon transport}

\subsection{Overseas development practice of low carbon transport}

\section{(1) UK}

UK is not only the country that pays close attention to the development of low carbon transport at the earliest in the world, but also one of the countries where the development of low carbon economy is relatively perfect. On December 4th, 1952, the Great Smog of London had lasted for 5 days in UK, which killed more than 4700 people infected with the respiratory disease. Within several months after the Great Smog, another 8000 plus people died an unnatural death. Therefore, the British government attached great importance to the development of low carbon economy. The Clean Air Act and Pollution Control Act were promulgated in 1956, 1968 and 1974 separately. In 1981, the British government issued the Administrative Measures regarding Motor Vehicle Fuel, which strictly specified the lead content in gasoline. In February, 2003, the "congestion charges" were charged within the range of $20 \mathrm{~km}$ around the city center of London, UK, while the traffic control policy was implemented at the region with the heavy traffic congestion. In order to satisfy the transport demand of central cities, the British government established the globally largest subway system in London. In July, 2009, the British government formulated The UK Low Carbon Transition Plan and issued the supporting documents, such as The UK Renewable Energy Strategy, The UK Low Carbon Industrial Strategy, Low Carbon Transport Strategy, and etc. In addition, the British government also established the Office for Low Emission Vehicles, the staffs of which were committed to actively strengthen the technical R\&D within the low carbon transport field and came from the Department for Transport, Department for Business, Innovation and Skills, and Department of Energy and Climate Change. In addition, the key emphasis in work of the Office was to support the identification of emerging technology within the extralow emission vehicle field [3].
(2) USA

The development background of low carbon transport in USA was similar to that in UK. The Los Angeles photochemical smog episode also occurred in USA in September, 1955. Afterwards, the American government also took variable measures to make the active treatment. In 1959, the Department of Motor Vehicles was established, which was responsible to monitor the motor vehicle exhaust emissions. In 1970, the Clean Air Act was issued. In 1975, the automobiles were required to install the catalytic converter. The Los Angeles required all vehicles sold after 1994 to install the "On-Board Diagnostics System", so as to conduct the real time monitoring upon the automobiles. Besides, the American government also encouraged the mass travelers to travel by bikes through the tax preference policy, and actively introduced the "Safety Green Box" plan, which effectively promoted the safety driving of bikes [4]. Furthermore, the development of American low carbon transport was benefited from the American strong ITS. Since 1990s, the USA has begun to intentionally and systematically develop the ITS, which effectively solves the American traffic congestion problem. In addition, the USA planned to solve the transport pollution and transport consumption problem by formulating the 2010 2014 ITS Five-Year Plan.

(3) France

The development practice of low carbon transport in France falls into three phases. Phase I was in 1970s. In this phase, the low carbon transport concept was not clearly proposed. However, since this phase, the French government's urban transport development planning has already played a positive role in promoting the development of low carbon transport. In this phase, the urban traffic congestion problem was mainly solved. The French government improved the traffic problems resulted from the increasing number of automobiles in cities by formulating the new flowline organization, implementing the road reconstruction and expansion, strengthening the road signal control and etc. Phase II started from the middle 1980s. In this phase, the urban transport pollution problem was mainly solved. The noise pollution, off-gas pollution and other problems resulted from the increasing number of automobiles went from bad to worse. A consensus was reached by all the local governments in France and they began to actively give priority to the development of public transport, especially the use of tramcar, which infused energy to the urban development. Phase III started from the middle 1990s. France issued the Travel Planning, which mainly advocated the development of slow traffic and intended to promote the development of low carbon transport through establishing the green street and trunk bus, and etc. In 1996, the French government issued the Atmospheric Protection and Energy Saving Act, which became the policy basis for the effective implementation of low carbon transport development. Besides, the government also worked out a series of measures to encourage the residents to select the multi-mode travel, established the integrated ticketing system of subway, high-speed rail and bus, and provided the bus subsidies 
to the specific groups. In addition, the unmanned bike rental system was also provided. The government specified that the number of vehicle operations will be declined by $40 \%$ till $2020[5]$.

(4) Singapore

The low carbon transport development in Singapore is highly effective. Although the land area of Singapore is very small, its road network density is still very large, which tops the list in the world. In addition, its traffic is very smooth. This is benefited from the effective transport management of Singapore government. The transport management of Singapore is quite distinctive, which is mainly demonstrated at the following three aspects. Firstly, the low carbon transport development of Singapore is conducted synchronously with the urban planning. In the early 1970s, the Singapore government continuously issued variable policies and measures, so as to avoid the possible traffic congestion in the future. In addition, Singapore integrated the comprehensive transport hub and the commercial and residential areas, so as to facilitate the travelers to transfer among variable means of transport and almost realize the seamless connection. Secondly, the growth of private cars are restricted via the economic lever. In Singapore, the car purchase cost of the residents is increased through raising taxes and other methods. Meanwhile, Singapore is also one of the earliest countries that collect the "traffic congestion charges", which increases the car use cost. In September 1998, Singapore took the lead in collecting charges upon the vehicles that entered the most crowded area of the city proper and partial highways within the specific time through the use of electronic toll collection system, so as to restrict the number of vehicles that entered the city proper at peak hour, and relieve the traffic congestion problem. Thirdly, the design and management are normalized. The Singapore's road planning design is very humanistic and the slow lane design is very reasonable. At the bus stop, there is the special awnings and sunshades, which facilitates people to travel by public transport. Meanwhile, there are very normative systems with regard to the parking management, driver's driving violation management and etc. Singapore is the highly legalized country and its strict traffic management and law enforcement regulations ensure the effective implementation of variable policies [6].

\section{(5) Japan}

Japan is called the "Mega Transport" country. The Ministry of Land, Infrastructure, Transport and Tourism is in charge of the transport affairs in Japan and it has very extensive powers. It not only manages the transport affairs, but also manages the housing, tourism and other affairs. This is resulted from the coordinated development of transport in Japan in 2001. After realizing the energy crisis, uneven development of national land and other problems, the Japanese government gradually expanded the powers of Ministry of Land, Infrastructure, Transport and Tourism, so as to facilitate the effective management of Japanese transport development problems. The most important feature of low carbon transport development in Japan is its very advanced rail transit, and the transport development is closely combined with the urban planning. For example, in Tokyo, the rail transit guides the expansion of its metropolitan area, which gradually develops it from the original single center to the multiple center. Such pattern effectively solves the traffic congestion problem existing in the central area. Besides, same as Singapore, Japan also constructs the comprehensive transport hub, shortens the transfer time and encourages the multimode travel. Meanwhile, Japan also applies the economic lever to control the transport demand [7].

\subsection{Development experience summary of low carbon transport both at home and abroad}

Although variable countries have different development background of low carbon transport and adopt the inconsistent means, it may be found that there are the following common characteristics in the development of low carbon transport through the understanding of low carbon transport development conditions of different countries:

(1) Early beginning. After suffering from the smog in 1950s, UK and USA attached great significance to the climate governance, further kept a watchful eye on gas emissions, and gradually controlled the low carbon transport. Such phased and gradual development strategy, laid a solid foundation for the development of low carbon transport, which provided a very good policy and legal environment and public opinion environment for the development of low carbon transport. France, Singapore and Japan controlled the transport by starting from the mitigation of traffic congestion. However, these countries generally have already drawn up effective plans before the occurrence of traffic congestion, which suppressed the occurrence of traffic congestion or weakened the possible traffic congestion.

(2) Relevant legislation safeguard. The aforesaid developed countries have the strict legislation system. Upon the development of low carbon transport, they have the matched legal systems to ensure the effective implementation of relevant policies. In addition, in case of the occurrence of transport violation acts or acts inimical to the development of low carbon transport, the relevant departments may ensure the strict execution as per the requirements of regulations.

(3) Government-leading and coordinated development. When these countries made the low carbon transport development planning, almost all the planning are combined with the urban planning. Upon the conduct of transport planning, the urban multi-center area, commercial area, school district and residential area shall also be effectively combined with the main transport hub, which not only avoids the repeated construction, but also improves the development efficiency of low carbon city. It is worth mentioning that every country has provided very convenient and humanistic facilities or services, when guiding the public to take the public transport and rail transit.

(4) Flexible use of economic lever. All the above countries have flexibly used the functions of economic lever. The UK, Singapore and Japan apply the economic 
lever to raise the use cost of private cars, while the USA and France apply the economic lever to motivate the public to select the low carbon travel. Although the application means of economic lever may vary, they still have the obvious effects upon the development of local low carbon transport.

\section{Main problems existing in the development of urban low carbon transport in China}

At present, the land utilization structures of many cities in China are the functionally integrated structures. The old city proper has the greater population density, which goes against the development of low carbon transport. Furthermore, the under-investment of urban low carbon transport, inadequate construction of urban low carbon public facilities and underdeveloped urban transport information form the main problems of low carbon transport development in China.

(1) The old land utilization structure is adverse to the development of urban low carbon transport.

The land utilization structure is the significant factor to affect the development of urban low carbon transport. At present, the land utilization structures of many cities in China are functionally integrated structures. The old city proper has the greater population density, which goes against the development of low carbon transport. For instance, in Beijing and many other metropolitans, for variable reasons, the functions are relatively centralized in the old city proper, which forms the single-center land utilization structure, causes the people flow and vehicle flow to become centralized and goes against the development of urban low carbon transport. Beijing municipal overall planning (2004 version) put forwards the "two axises, two belts and multiple centers" layout proposal, which still fails to reach the expected effects. Especially, with the advent of automobile age, the single-center land utilization structure become more adverse to the development of urban low carbon transport [8].

(2) Under-investment for development of urban low carbon transport

The bus is the relative low-carbon means of transport, but the bus is obviously under-invested in China. In 2010, China's urban public transport industry completed the fixed asset investment of 236.07 billion RMB, which only accounts for $8.5 \%$ of the total investment for fixed assets of the national transport industry. In addition, the investment for the railway fixed assets within the same period accounts for $27 \%$. Generally, the fiscal subsidy rate of large and medium-sized cities upon the public transport facilities newly built by the public transport enterprises is less than $10 \%$. Due to the financial underinvestment, the urban public transport enterprises face difficulties in their business operation. As the typical low-carbon means of transport, the subway has the construction cost of $0.7 \sim 0.8$ billion RMB per kilometer in average. Most local governments have much stronger demands upon the rail transit. However, subject to the financial restrictions, it is hard to carry out the largescale subway construction.

(3) Inadequate urban low carbon public transport facility construction

China has always been devoted itself to the construction of urban transport facilities, but its construction speed is lagged far behind the growth of motor vehicles and traffic flow. The public transport does not play its due role in mitigating the urban congestion and constructing the low carbon transport, and etc. At present, China's urban public transport density is not enough and the use is not convenient. As a result, the citizens prefer the use of automobiles. China's urban public transport mode share is less than $10 \%$, and the public transport mode share of metropolis is only about $20 \%$. In recent years, public transport mode share of metropolis in China has been declined by about $6 \%$ in average, while the public transport mode share of big cities in Europe, Japan, South America and other regions reaches $40 \% \sim 60 \%$. Due to the rapid growth of motor vehicle number, the environmental pollution of transport becomes the increasingly serious.

(4) Underdeveloped urban transport information

The existing urban transport information service level in China is much lower. At present, only Beijing and other 10 plus cities in China have established the public transport information platform with the single function, which is not connected to the network with the remaining systems. Compared with Japanese VICS, European RDS/TMC, American 511, London's travel portal website and other successful transport information platforms, there is still a greater gap.

\section{Countermeasures and suggestions regarding the development of low carbon transport in China}

The international experiences of urban low carbon transport development are mainly as follows: the urban decentralization will be applied and the transportfriendly land utilization mode will be adopted; the taxes, subsidiaries and other policies will be utilized to guide the urban low carbon consumption; the coverage density of urban public transport system will be improved; the information communication shall be increased, so as to reduce the carbon emissions of variable means of transport during the efficient operation and seamless connection process; the urban transport-low carbon emission district will be established.

Internationally, there are three basic methods for the development of urban low carbon transport system: avoidance, transfer and improvement. Among them, avoidance refers to the avoidance of occurrence of unnecessary traffic volume. It is required to fundamentally reduce the traffic volume through the urban decentralization, adjustment of land utilization structure, implementation of remote office, and etc., so as to reduce the carbon dioxide emissions. Transfer refers to transfer the commodities and passengers to the low carbon means of transport. It is required to transfer the traffic volume undertaken by the original high carbon 
emission means of transport to the low carbon emission means of transport, so as to achieve the target of reducing carbon dioxide emissions under the premise that the commodity and passenger transport volume is the same. Improvement refers to the carbon emissions of unit mileage for the means of transport. It is required to improve the technical level of the original means of transport, and reduce the carbon emission index of unit mileage, so as to achieve the effect of reducing the carbon dioxide emissions under the premise that both the means of transport and travel distance are same.

With reference to the overseas experiences regarding the development of urban low carbon transport, and in combination with China's national conditions, the following countermeasures may be taken for the development of urban low-carbon transport [9]:

(1) The urban transport development planning shall be perfected. In the long run and in combination with the urban functional zoning, it is required to optimize the urban transport layout network and construct the comprehensive transport hub, so as to realize the "seamless connection" and "zero transfer" of multiple means of transport, and form the urban green comprehensive transport system in which the public transport is the main travel mode. It is required to perfect the network layout of public bike system. It takes the realization of overall coverage of public bike network in the whole city as the target, and intends to gradually recover and open the bike special way, so as to guide the green travel.

(2) It is required to energetically develop and perfect the bus and rail transit. It is required to adhere to the buspriority policy, optimize the bus route and energetically promote the construction of micro-circulation road. It is required to accelerate the construction of rail transport, bus rapid transit (BRT) and intelligent transport management system, and give priority to promote the central city rail transport construction. In addition, it is required to energetically improve the service quality of bus and rail transit, so as to enable the public transport to become the preferred travel mode for the public.

(3) It is required to strengthen the energy saving and emission reduction management of automobiles. It is required to adjust the energy structure of urban transport and energetically develop the clean energy. The market access method will be utilized to accelerate the elimination of old automobiles and control the development of high oil consumption and high pollution motor vehicles. In addition, it is required to intensify the efforts to construct the automobiles parking lot, battery charging area and other supporting infrastructures, and promote the development of energy-efficient vehicles. Meanwhile, the transport enterprises are encouraged to innovate the energy-saving technology and use the energy-saving and environmental protection vehicles, new energy vehicles and electric vehicles. The enterprises and residents are encouraged to conduct the carbon trading within the transport field.

(4) It is required to establish and perfect the low carbon development policies and standards for variable means of transport, and establish the industrial low carbon evaluation system. It is required to accelerate the formulation of low carbon development policies for the road, waterway, rail, railway and other means of transport, and perfect the relevant standard specifications as per the low carbon transport requirements. In addition, it is required to improve the market access threshold from the low carbon transport perspective, establish the exit mechanism, and strengthen the transport market and vehicle management for variable means of transport.

(5) It is required to improve the transport management level. It is required to take effective measures to mitigate the urban traffic congestion problem. It is required to conduct the optimization and control upon the intersections and signal lamps, strengthen the construction of mobile signal system and the road camera equipment, and establish and perfect the transport management center. Meanwhile, it is required to timely acquire the road conditions information and provide the real time road conditions navigation. In addition, it is required to improve the transport administrative management, strengthen the team building and enhance the service level.

(6) The transport industrial association shall strengthen the industrial self-discipline, promote the energy-saving transport facilities and equipment, and carry out the low carbon transport educational propaganda and low carbon transport exchange and cooperation.

(7) The transport enterprises and residents shall actively implement the low carbon regulations, policies and standards, and actively participate in the low carbon trading and low carbon services and travels. The enterprises strive to promote the low carbon technical progress and strengthen the energy saving and emission reduction works of the vehicles.

(8) It is required to intensify the efforts to propagandize the low carbon transport via variable means. It is required to fully utilize the newspapers, bulletin boards, TVs and other medias to vigorously promote the low carbon transport concept and initiate the low carbon transport travel, so as to enable the enterprises and residents to build up the low carbon transport concept and form the dense atmosphere for development of low carbon transport.

\section{Conclusion}

The carbon dioxide emission within the transport field is a sort of rigid carbon emission. As China's modernization process constantly goes deeper, the industrial energy consumption gradually declines. However, the energy consumption of transport will continue to rise. Finally, the energy consumption of transport will account for about $30 \%$ of the total energy consumption [10]. Therefore, it is required to define the emission reduction target within the transport field, pass through the concept change, science and technical support, system innovation and structural transformation, play the strong leading function of China's government, and properly implement the existing variable national requirements and measures of response to climate change, so as to coordinate the development of China's 
transport with environmental protection, and realize the low carbonization and modernization of transport [11].

\section{References}

1. Tu Jianhua, Countermeasures and Suggestions regarding the Development of Low Carbon Transport, Journal of Transport Management Institute Ministry of Transport, 2015, 25 (2): 13-16.

2. Zhang Liang and Zheng Dayong, Healthy Development of China's Low Carbon Transport with Reference to International Experiences of Low Carbon Transport, Auto Industry Research, 2011 (7): 26-29.

3. Cui Dongchu and Yu Yue, International Experience of Low Carbon Transport and Its Implications for China, Ecological Economy, 2014, 30 (9): 68-72.

4. Zhou $\mathrm{Ke}$ and $\mathrm{Li}$ Shanshan, Experience and Enlightenment regarding the Policies and Laws of the American Low Carbon Transport, Legal Daily, 2012-03-28 (12).

5. Yao Yin and Ou Guoli, Development, Change and Enlightenment regarding the American policies of Intelligent Transport System, Comprehensive transport, 2009 (5): 80-83.

6. Characteristics and Enlightenment of Singapore's Road Transport Management, Practice and Theory of SEZS, 2013 (3): 59-63.

7. Feng Yuwen and Zhang Xiaozhe, The Enlightenment of International Metropolis's Low Carbon Transport Pattern upon Xi'an from the Spatial Perspective, Journal of Shaanxi Institute of Socialism, 2014 (1): 48-52.

8. Development of China's Urban Low Carbon Transport with Reference to International Experience, China Economic News Net, January 3rd, 2013.

9. Sun Dehong, Development Pattern and Measures of Urban Low Carbon Transport, Transport and Environmental Protection, 2011 (1): 43-48.

10. Chen Lei and Zhang Yumu, Rigid Carbon Emissions are Imperative, Science and Technology Daily, 2009.12.2 (7).

11. Zhang Yunxia, Discussion on the Development of Domestic Low-Carbon Transport in the Process of Modernization, Science and Technology Management Research, 2011 (12): 86-88. 